\title{
MENTAL HEALTH SERVICES IN AN ENGLISH COUNTY BOROUGH BEFORE 1974
}

\author{
by
}

\author{
HUGH FREEMAN*
}

IN 1974, local government reorganization saw the end of Salford as a county borough and its transformation into a metropolitan district with a population more than twice as large. That year may be a suitable point from which to look back and examine the evolution of its mental health services. Though outwardly part of an endless conurbation which covers much of south-east Lancashire and neighbouring areas, Salford has a long history as a community, and has always been a place with which people identify strongly. Of overwhelmingly working-class composition, its culture has been characteristic of industrial Britain since the early nineteenth century. As the author has been personally associated with the psychiatric services there since 1961 , this paper is, to some extent, the result of participant observation.

\section{EARLY DEVELOPMENTS}

Eighteenth-century Salford was a very small town, with some cottage-type textile industry, surrounded by fertile agricultural land; in 1801, there were only 18,000 inhabitants, but with the onset of industrialization the population increased between 1821 and 1831 by sixty per cent, and in the next decade by seventy per cent. By 1881 , it had reached 176,000 and was larger than that of Newcastle upon Tyne, all within an area of less than eight square miles. The local government situation was then chaotic, and it was not until 1891 that a unified county borough was fully established. As far as the care of the mentally ill was concerned, the county asylum in Lancaster was opened in 1816, but because of the rapid increase in population, which made Lancashire the most populous county in England by 1841 , it soon became very overcrowded. A second hospital, at Prestwich, was inaugurated in 1851. Although no specific data are available, the numbers of mentally ill admitted from Salford to asylums must have been very small until about the last quarter of the century because of the small number of available beds; by then, additional mental hospitals had been opened - at Whittingham, Rainhill, and Winwick - but they had many other large populations in Lancashire to serve as well as Salford. Undoubtedly, significant numbers of mentally ill paupers must have been admitted to the workhouse in Salford, as throughout the country, where they were part of a heterogeneous body of sick, disabled, and destitute people. The overcrowding of the workhouse, in spite of the inauguration of a large new one in 1852, and steadily increasing numbers of the sick resulted in the opening of the Salford Union Infirmary (now Hope Hospital) in 1882. Like other hospitals of its kind, this one contained a mental observation ward, to which mentally disturbed

* Hugh Freeman, MSc, MA, BM, BCh, FRCPsych, DPM, Consultant Psychiatrist, Salford Health Authority, Hope Hospital, Salford M6 8HD. 


\section{H. Freeman}

patients were brought, and either recovered there or were transferred, on a magistrate's certificate, to a mental hospital.

When the county and county borough councils were set up, following the Act of 1888, these new authorities took over the management of mental hospitals. However, in Lancashire and the West Riding of Yorkshire, the situation was complicated by the large number of county boroughs contained geographically within these counties. Therefore, an Asylums Board was set up in each, which managed the hospitals on behalf of the respective county and, in the case of Lancashire, of seventeen county boroughs, including Salford. The mental deficiency institutions, when they were later established, were also operated through the same organizations. Following the 1929 legislation ending the Poor Law, the Salford Union Infirmary was taken over by the local authority Public Health Committee, and other Poor Law activities by its Public Assistance Committee. However, these latter functions included the employment of Relieving Officers, amongst whose duties were the compulsory admission of patients to mental hospitals under the Lunacy Acts, but no longer to workhouses after 1930 . The Lancashire Asylums Board was renamed the Lancashire Mental Hospitals Board.

Until the inception of the National Health Service (NHS), Salford's Public Health Committee, through its Hospitals Sub-Committee, governed the smallest details of activity in the two city hospitals; for instance, its minutes show that each time an anaesthetic was given, the Medical Superintendent had to obtain approval at the subcommittee's next meeting for the anaesthetist's fee of $10 \mathrm{~s} .6 \mathrm{~d}$. to be paid. ${ }^{1}$ Although the Labour Party began to achieve a dominating position in the council during the 1920s and 30s, as it did in the last few years of the Board of Guardians, it did not dispute the need for "economy". At this time, local authorities received little financial help from the Exchequer, and whoever was in control was constrained by the fact that Salford contained some of the worst problem areas in the country, together with relatively low rateable resources $-£ 58 s$. per head in 1939 , compared with an average of $£ 7$ for the English county boroughs. The population, which reached a peak of 247,000 in 1927 , then began to decline, and has done so continuously ever since.

During the 1930s, after-care work in mental health was undertaken by local Mental Welfare Associations, which received financial help from the Lancashire Mental Hospitals Board. They appointed social workers, who operated from four centres Manchester, Liverpool, Blackburn, and Preston - and undertook the statutory extramural responsibilities of local authorities in connection with mental defectives. According to Jones, ${ }^{2}$ these workers, who were almost all women, "were generally prepared to undertake... duties where an obvious need arose" in relation to patients discharged from mental hospitals. However, the Relieving Officers, who handled statutory duties with the mentally ill, were almost all men. As a result of these arrangements, the Medical Officer of Health (MOH) and Public Health Committee had no responsibility for the in-patient mental hospital treatment of Salford people, nor for their after-care.

In 1940, the part of Hope Hospital which included the mental observation unit was completely destroyed by bombing; there were then no psychiatric beds within the city.

\footnotetext{
1 Salford City Archives.

${ }^{2}$ K. Jones, 'Problems of mental after-care in Lancashire', Soc. Rev., 1954, 2 (New Series): 34-56.
} 


\section{Mental health services in an English county borough before 1974}

The nearest unit of this kind was at Park House, Manchester, later renamed Springfield Hospital, which was made available for Salford patients. However, in 1944, Salford Royal Hospital (then a voluntary one) established a psychiatric outpatient clinic - one of the first such services to be started in the North of England. It was not restricted to residents of Salford, and patients came to it from long distances, by urban standards, because of the lack of similar facilities elsewhere. It provided minor psychotherapy and such medication as was available then, as well as out-patient electroconvulsive therapy (ECT), though under extraordinarily difficult conditions.

\section{THE NATIONAL HEALTH SER VICE}

The functions of the Lancashire Mental Hospitals Board were taken over in 1948 by the Manchester and Liverpool Regional Hospital Boards (RHBs); at first, no catchment areas were laid down, and no central bed bureau was established in either region, the task of finding a place in hospital for any patient being left to individual Duly Authorized Officers (DAOs) (see below). The result was that "DAOs are frequently forced to contact one hospital after another in search of a bed for an urgent case. One local authority [in Lancashire] was found to have patients in thirteen different [mental] hospitals, and it is not unusual for one hospital to receive patients from an equal number of areas." ${ }^{3}$ This can be confirmed in the case records of some Salford patients who had recurrent psychotic illnesses in the 1940s and 50s; sometimes, each successive admission was to a different mental hospital; the problems likely to result from the lack of continuity of care and distance from the patient's home are obvious.

Nevertheless, between 1948 and 1956, cases from Salford requiring mental hospital admission generally went to Prestwich Hospital; most admissions were compulsory, and a bed there could only be obtained by a DAO - not by an outside doctor. The hospital had over 3,000 occupied beds and a local reputation that was hardly enviable; it maintained no working contact with services outside, though some time after discharge, the local authority Health Department would receive a form, giving the patient's name and age, and the section of the Lunacy Act under which he had been detained, but no other information.

With the coming of the NHS, similar out-patient facilities to those at Salford Royal were established at Hope Hospital, together with a few beds. Because of the destruction of the "mental block", these were simply within a male and female medical ward respectively, and had no special facilities attached to them, except a small room for occupational therapy. The psychiatric conditions which could be treated in these circumstances were obviously very limited, and it had to be fairly well guaranteed that no disturbance was likely. Should this unfortunately happen, a DAO would be called, and the patient removed to the mental hospital; there were then no nurses with psychiatric training at Hope.

Though in general principle the NHS was comprehensive, administratively, it was tripartite - hospitals, general practitioners (GPs), and local authority services, all with separate administrations. Working co-ordination between the different branches was certainly possible - where there was the will to achieve this - but it became clear before long that such a will was generally absent or weak. In the case of Prestwich

${ }^{3}$ Ibid. 


\section{H. Freeman}

Hospital, attempts to integrate local authority social workers into its activities on a continuing basis were unsuccessful. Since a mental hospital of this sort is a closed system, with a peculiar culture of its own, it is almost inevitable that it should be fundamentally hostile to staff working outside; they would be seen as the bringers of extra burdens, rather than as colleagues with whom tasks could be shared.

Rehin and Martin" point out that "The basic fact that in 1948 all citizens acquired the right of unrestricted access to a GP of their choice ... opened up possibilities ... of early diagnosis of mental as well as physical disorder and of treatment and care, with or without specialist supervision, in a domiciliary setting." The possibilities certainly were there, and even today, the overwhelming bulk of psychiatric disorder in Britain continues to be handled at the primary care level - though not always recognized. ${ }^{5}$ But when the NHS began, most GPs in practice had received no more than minimal psychiatric teaching, and had a pathetically ineffective range of medication available to them; at the same time, psychiatric specialists were very few, and consultations or treatment from them difficult to arrange outside London. Psychotherapy was in its infancy, though astonishingly enough, two trained psychoanalysts, both German refugees, were practising part-time in Salford - one in the hospitals (he died in 1961) and one in the child guidance clinic.

The post-war period was one of rising admission rates to psychiatric beds, which were then very largely in mental hospitals; this reflected public awareness of more effective treatment being available (particularly ECT) and also probably a greater acceptance of psychiatric intervention, which may well have been related to the active part played by psychiatry in the armed forces. Although average lengths of hospital stay were reduced, pressure on psychiatric beds became very considerable, and it was felt by many hospital authorities that extra mental hospital accommodation would have to be built. Fortunately, due to several factors - of which the minimal capital spending on hospitals of all types during that period was the most important - no such extensions of mental hospitals were carried out. In 1950, the Manchester RHB rejected a proposal to base its mental health services at four large mental hospitals, with peripheral clinics in other hospitals, staffed by mental hospital doctors. ${ }^{6}$ The Board considered this alien to the comprehensive principles of the NHS, and felt it would only serve to divorce the diagnosis and treatment of mental disorders still further from the broad stream of general medicine. Instead, it decided that consultant psychiatrists should eventually be appointed to all general hospital centres in the Region, but that each psychiatrist would also be on the staff of a mental hospital, and would have full clinical charge of a number of beds there. As a result of the Board's decision, psychiatric units were developed from the former mental observation wards in ex-public assistance hospitals at Oldham, Bolton, Burnley, and Blackburn, and then in other Lancashire towns. Salford was unable to participate in the early stages of this comprehensive development because of the loss of its mental observation accommodation in World War 2, though out-patient work was being done there on a con-

\footnotetext{
4 G. F. Rehin and F. M. Martin, Patterns of performance in community care, London, Oxford University Press, 1968.

s D. P. Goldberg and P. Huxley, Mental illness in the community, London, Tavistock Publications, 1981.

- Manchester Regional Hospital Board, Minutes, 1950.
} 


\section{Mental health services in an English county borough before 1974}

siderable scale. One thing which became clear before long, though, was that the links which the RHB had intended to maintain between the new general hospital units and the mental hospitals had failed to become real. The general hospital psychiatrists found it more effective to "consume their own smoke", i.e. to use only the beds they had within their own units for patients of all lengths of stay; amongst other things, this avoided the reluctance felt by many patients and their relatives about transfer to a mental hospital.

These general hospital developments - which did not occur on a similar scale in any other part of the country until many years later - were extremely influential on the views of senior doctors within the Ministry of Health, who had the crucial role in deciding national policy. They were beginning to feel that the classical model of the mental hospital, largely unchanged for over a century, was no longer relevant to modern conditions; now, there was proof that a possible alternative existed, which was much more in keeping with the general ethos of the NHS. From then on, any plans by RHBs for new or enlarged mental hospitals would be particularly discouraged, while national policy started to move in the direction of a general hospital-based system, with each service having responsibility for a defined population. ${ }^{7}$ A change in emphasis can be seen in the Annual Reports of the Chief Medical Officer, Ministry of Health, in the mid-1950s, and this becomes clear by $1958 .^{8}$.

In 1956, the Manchester RHB decided on a change of catchment areas, and Salford was now allocated to Springfield Hospital, which was much smaller than Prestwich, but equally backward. Geographically, it was also about half a mile from the Salford boundary. Springfield was also to serve two Health Divisions of Lancashire County, adjacent to Manchester or Salford, but as in the case of Prestwich Hospital, its longstay population came mostly from the City of Manchester. Working arrangements were in general much the same as those described above for Prestwich Hospital, though Springfield's one PSW started monthly meetings with DAOs from the three local government areas now served by the hospital. These, however, did not generate any sense of common purpose, and became little more than exchanges of grievances.9

Susser ${ }^{10}$ wrote of this situation:

none of these agencies could know anything about the flow of patients from one to another. Agencies had vague notions of the services provided by each of the other agencies, and whom they were serving. They knew little of the characteristics, and even of the bare numbers, of the populations they themselves served. Consequently, they did not perceive the fragmented and fragmentary nature of the care they offered, nor could they perceive the extent of interdependence needed were they to provide a full range of services for their patients. They were largely unaware of the disruptive effects on patients of discontinuity of care, and each professional tended to see and assess the needs of his patient from his own isolated vantage point. Each autonomous organization put constraints on the perception of the professionals working within it, in terms of its own functions and aims.

${ }^{7}$ H. L. Freeman, 'District psychiatric services', in P. Bean (editor), Mental illness: changes and trends, Chichester, Wiley, 1983, pp. 351-378.

G. C. Godber, personal communication.

9 M. W. Susser, 'Changing roles and coordination in mental health services', in P. Halmos (editor), Sociological Review Monograph No. 5, University of Keele, pp. 61-90, 1962.

${ }^{10} \mathrm{M}$. W. Susser, 'Psychiatric registers and community mental health services', in B. H. Kaplan, R. N. Wilson, and A. H. Leighton (editors). Further explorations in social psychiatry, New York, Basic Books, 1976, pp. 95-109. 


\section{H. Freeman}

\section{LOCAL AUTHORITY SER VICES}

Until 1948, local authorities in Lancashire had no experience of any form of aftercare work with the mentally disordered; however, they then each became responsible for setting up a Mental Health Department within the Health Department, of which the $\mathrm{MOH}$ was chief officer. Circular $100 / 47^{11}$ defined the main functions of these proposed new departments as: (1) The appointment of "officers duly authorized to take initial proceedings in providing care and treatment" for the mentally ill. (2) Ascertainment, supervision, and training or occupation of mental defectives, as well as securing institutional care or guardianship of them in appropriate cases. This was an extension of the authorities' duties under the Mental Deficiency Acts, 1913-27. (3) "Generally - the power, and to the extent that the Minister directs, the duty, to make arrangements for the care and after-care of persons suffering from mental illness or defectiveness." This latter was a re-statement, in relation to a particular group of clients, of the vague powers of Section 28 (1) of the NHS Act for prevention, care and after-care. The Minister, in fact, never did direct any particular action in this respect a position which is still unchanged.

With the abolition of Public Assistance and the final separation of psychiatric services from relief of the poor, the Relieving Officers who came into the new Health Departments were renamed Duly Authorized Officers (DAOs), presumably because no one could think of anything better. The function of relieving financial distress was taken over by the National Assistance Board and its local officials. Other recruits to the new cadres of DAOs were mainly mental nurses - a group who had a completely different background from the Nightingale tradition of general nursing, which was overwhelmingly female; they were predominantly male, and more closely related to armed forces medical orderlies. In late 1947, the Salford Health Committee decided to recruit a part-time psychiatric social worker (PSW) for Hope Hospital, but this was not to become effective until after the Appointed Day, so that no cost at all was to fall on the local authority. However, by 1953, Salford local authority employed six mental health staff (excluding those engaged in full-time administrative or clerical duties) which was more than in any other county borough in Lancashire, apart from the far larger Manchester and Liverpool. Bolton, with a slightly smaller population, had only two staff then.

The DAO had a peculiarly anomalous position; under the Lunacy Act, he could decide on his own account to admit a patient compulsorily to a mental hospital for three days or obtain a magistrate or doctor to approve a longer period, and he secured the bed himself by negotiation with the hospital. Thus, he exercised responsibilities which in many respects were characteristic of a profession, and was legally accountable for them as such; yet in terms of training, qualification, and status he occupied a fairly lowly position, with practically no possibility of advancement. In practice, the skill and experience of DAOs in assessing psychiatric problems were relied on a good deal by GPs, hospitals, police, and other welfare services, yet this was unacknowledged as a "professional" type of relationship. Mountney ${ }^{12}$ points out that

\footnotetext{
1 National Health Service Act 1946: provisions relating to the Mental Health Services, London, Ministry of Health and Board of Control, 1947.

12 G. H. Mountney, unpublished MS on social work in the Salford Mental Health Service, 1971.
} 


\section{Mental health services in an English county borough before 1974}

local authority mental health workers had a vulnerable position as a primary level of service which, like that of GPs, was legally required to respond to every demand made on it. Should anything go wrong, they would be likely to be judged by administrators and council members, who might well have only a remote idea of what their work entailed. Although nominally under the supervision of the $\mathrm{MOH}$, there was virtually no one to whom they could turn for professional - rather than administrative - advice; MOHs had no psychiatric training and it was rare for any Health Department to employ a doctor who had. In Salford and certain other places, the DAOs were generally referred to as "mental health officers".

Under the NHS Act, local authority functions in mental health were almost entirely permissive, and very few authorities sought to do more than the minimum. Unlike the directive policies followed by Government departments in such fields as education or child care, the Ministry of Health had a tentative approach to mental health services, and rarely intervened as long as minimal duties were carried out. Furthermore, the bureaucratic rigidity and pennypinching routines, which were then a general characteristic of local government, made development and innovation extremely difficult. However, Salford was fortunate in having an unusually enlightened $\mathrm{MOH}$, Dr J. L. Burn; though his interests in promoting the health of the community were wide (and the appalling environmental conditions of much of the population gave much scope for these), mental health was always a special priority for him. The first actual facility for the mentally ill to be provided by the local authority, outside its statutory obligations, was a therapeutic social club. This began in 1952, on one evening weekly, and catered mainly for discharged mental hospital patients; however, it was attended by some of the DAOs and thus provided an opportunity for informal after-care.

This development was followed by the opening in 1956 of a day centre for females, also mostly ex-mental hospital patients. It was in one room of a child welfare clinic, where it was tolerated with a very ill-grace, and operated on weekday afternoons only. The staffing consisted of one unqualified handicraft teacher, who achieved a remarkable amount through sheer ingenuity, in almost impossible conditions. In the same year, Dr Burn overcame the extreme local shortage of psychiatrists by an arrangement with the Department of Social Medicine at Manchester University, whereby doctors and research workers from the university worked part-time in the city; they were not psychiatrists, but had a primary interest in mental health. No significant help was available from local hospitals, as it was, for example, in Croydon or Nottingham, at a consultant level. The fact that the initiative towards co-ordination was taken here by the local authority resulted in a very unusual situation - probably the only comparable instance, though of a somewhat different nature, was in West Ham. ${ }^{13}$ As a result of this collaboration of academic doctors and semi-professional mental health officers, which was almost certainly unique in Britain, several objectives were formulated.

The first was to provide a system of in-service training for the DAOs; at that time, no possibility of formal training existed for them unless the officers were to go through

${ }^{13}$ J. H. Kahn, 'The Newham community mental health service', in H. L. Freeman and J. Farndale (editors), New aspects of the mental health services, Oxford, Pergamon Press, 1967, pp. 563-591. 


\section{H. Freeman}

the difficult process of qualifying as a PSW. The fact that the Manchester University PSW course then took only six entrants per annum indicates how difficult this was likely to be. The main new vehicle of training in Salford was through the weekly case discussions, which began in 1957; as well as providing information, these made the officers look critically at their work, provided morale and cohesiveness to the service, and allowed the social workers to share some medical prestige.

The second objective was to increase the provisions of extra-hospital community facilities. In 1959, a small day centre was opened for men (mostly chronic schizophrenics), which also consisted of little more than one room in an old house; however, it was to be remarkably successful for some years in restoring such handicapped men to employment. During the same year, the social club expanded greatly, partly because several of the university staff attended, which acted as a catalyst for the activities of members. A separate social club was also started for the severely subnormal, in collaboration with a voluntary organization; (facilities for the mentally subnormal will not be considered in detail in this paper).

The third objective was to improve co-ordination between the agencies involved, the discontinuities between them being enormous. For instance, the general hospital psychiatric service had no formal link with the mental hospital, so that any of their patients needing admission to the latter had to be referred first to the local authority department; DAOs could not see patients in the mental hospital between admission and discharge, while the minimal information received from the mental hospital meant that after-care could not be co-ordinated with it; inadequate staffing in the general hospital service meant that out-patient appointments were difficult to obtain, and DAOs often had to admit patients to the mental hospital because they could not obtain psychiatric assessments in any other way. ${ }^{14}$

The MOH's Report for 1957 showed an increased volume of work by the Mental Health Department, in spite of a falling population. In that year, it dealt with 614 cases, compared with less than half that number in 1949 - the first full year after the inauguration of the NHS and of the Department itself. As well as increased numbers, there appeared to have been a change in the type of case being referred, not all requiring urgent hospital admission; less than half the notified cases in 1957 were admitted to mental hospital, compared with over two-thirds in 1949. Also, the number of voluntary admissions during the previous four years had trebled, whereas the number of compulsory admissions under the Lunacy Act had remained steady; a significant number of cases were being dealt with, primarily or wholly, by supportive visits from DAOs. The 1958 Report stated that about eighty-five per cent of psychiatric hospital admissions from Salford were being made through the local authority service.

The MOH's Report for 1959, surveying all patients from Salford referred for any form of psychiatric care in that year, stated that out of 430 referrals by GPs, 224 were to the local authority, 176 to general hospital out-patients, and twenty-six to other psychiatric units. Of these referrals to the City Mental Health Department, sixty-one per cent were admitted to mental hospitals, seventeen per cent remained in the care of social workers, fourteen per cent were referred to out-patient clinics and eight per cent had other disposals. However, total referrals to the Department for that year were

${ }^{14}$ City of Salford, Report of the Medical Officer of Health for 1959. 


\section{Mental health services in an English county borough before 1974}

496, of which 151 were from other social agencies and forty-five from general hospital out-patient clinics, in addition to those from GPs and relatives. In 1959, for the first time, the Mental Health Department carried out more voluntary than compulsory admissions, i.e., fifty-six per cent compared with thirty-nine per cent in 1958. During the same year, an attempt was made to formalize the GP-social worker relationship by allocating each DAO to a group of general practices, rather than to a geographical area of the city. The practical results of this were very mixed, but were governed almost entirely by the view which each GP took of the relationship; because of their equivocal status, the DAOs themselves could exercise very little influence on the situation. Susser ${ }^{15}$ states that "the sharing of reponsibility indicated recognition for social workers by a powerful, long established group of high social prestige" - but this did not happen very often, and to give the GPs their due, there were no rules at the time to guide them in such delegation. In the same year, a chapter by Dr Burn ${ }^{16}$ gave examples of activities of social workers in a progressive mental health service; these included the preparation of the family to receive a member from hospital, assisting patients to run their day-to-day affairs, assistance in finding suitable work, and preventing isolation and neglect of old people.

Though Salford was fostering the development of its Mental Health Department into a social work agency, the country's most important local authority took a precisely opposite view. Lawson, ${ }^{17}$ who studied compulsory admissions to a London observation ward in 1959, concluded that the London County Council's (LCC) policy was to regard the function of its Mental Welfare Department as that of an emergency service - "... the DAO was thus to visit as many people referred to the department as he could, to take such action as he thought necessary ... and only if he decided that admission... was not necessary was he to consider alternative action". Family and social stress were regarded as the business of the PSW Department of the LCC, but contact between the two departments was minimal.

\section{THE MENTAL HEALTH ACT 1959}

In the period following the inception of the NHS, there was much consciousness of change in psychiatry as a whole, even though most hospitals lumbered on in the traditional way, but more overcrowded than ever. However, the arrival of refugee European psychiatrists (mostly with psychodynamic interests), and the development of therapeutic community and group therapy techniques within the armed forces, had provided the possibility of alternative approaches; at the same time, incorporation of psychiatry into the general framework of the NHS began to make it more like other specialities, rather than a world of its own. Furthermore, the old certainties and social deference of the pre-war world had been severely shaken, so that there was a general questioning of the legitimacy of institutions, including mental hospitals - though this was only a foretaste of what was to come twenty years later. Perhaps most important of all was the fact that in ECT (and to some extent leucotomy), psychiatry at last had

${ }^{15}$ M. W. Susser, Community psychiatry, epidemiologic and social themes, New York, Random House, 1968, p. 251.

${ }_{16}$ J. L. Burn, Recent advances in public health, London, J. \& A. Churchill, 1959, pp. 310-333.

17 A. R. L. Lawson, The recognition of mental illness in London, London, Oxford University Press, 1966. 


\section{H. Freeman}

a specific treatment method that was effective in major mental illness, and one that could often be used on an out-patient basis. This, together with the development of both individual and group techniques of psychotherapy, meant that there were huge numbers of potential psychiatric patients for whom the mental hospital in the old sense was completely inappropriate.

With the mental hospital went a whole paraphernalia of restrictive law, mainly embodied in the Lunacy Act of 1890 as amended by the Mental Treatment Act 1930. It came increasingly to be felt that progress in mental health services was being seriously impeded by obsolete provisions of the law, and the Percy Royal Commission was set up in 1954 to examine this. Its report of 1957 was almost totally embodied in legislation two years later - which must constitute some sort of record. If, as Jones ${ }^{18}$ states, 1890 was the "Triumph of Legalism", then 1959 was the victory of the medical model. While the Act cleared away a huge jungle of outdated legislation, and provided a new system for compulsory admissions which was almost wholly medical, it made no change in the duties of local authorities towards mental health. They were still obliged to employ staff - now renamed Mental Welfare Officers (MWOs) - who would undertake compulsory admissions when necessary, but there was still no requirement for these people to have any training or qualification. Although the preamble to the Act supported the principles of informal, non-institutional care, and local authorities were given wide permissive powers to provide extramural facilities specifically mentioning hostels - it was still up to them whether they did so or not. Things could have been improved if the Government of the day had "earmarked" for mental health purposes some of the Exchequer money allocated to local authorities, but it refused to do so, as has every succeeding government.

The other significant change that came with the Mental Health Act was that whereas completion of a certificate under the Lunacy Act involved automatic admission to a mental hospital, the new compulsory procedures only made admission possible. Those undertaking these procedures then had to negotiate for a bed, which might not be easy, and particular problems soon emerged in the case of patients coming from courts under Hospital orders. On the whole, this was a positive development, since it meant that professional staff outside mental hospitals could not automatically get difficult people off their hands by going through some legal formalities. However, if the doctor and social worker taking action outside also had responsibilities within the hospital, then many of the difficulties would be removed as later developments in Salford demonstrated.

In Salford, the only change resulting directly from the inception of the Mental Health Act in late 1960 was that Springfield Hospital ceased its routine notification of discharges to the local authority Health Department. Though this had not been a very effective form of co-ordination, it evidently served some function, since in the subsequent six months, over fifty per cent of discharges in the first three months of the Act's operation were referred to the Department through other sources. ${ }^{19}$ At about the same time, the RHB responded to prolonged pressure from the local authority and agreed to establish a new post of a consultant psychiatrist, who was to have sessions at both

${ }^{18} \mathrm{~K}$. Jones, $\boldsymbol{A}$ history of the mental health services, London, Routledge \& Kegan Paul, 1972.

19 City of Salford, Report of the Medical Officer of Health for 1961. 
the mental hospital and the general hospitals serving Salford. The present author was appointed to the post in 1961, and was subsequently appointed Honorary Consultant to the City Health Department; at that time, such a comprehensive arrangement was extremely rare in Britain.

Following this, the principle of geographical sectorization was introduced by the Medical Advisory Committee at Springfield Hospital - any patient coming from an address in Salford was to come under the present author's care, unless he had been specifically referred to another consultant (which, in practice, occurred in very few cases). Also, all medium- and long-stay patients who had originally come from addresses in the city were placed under the same consultant's care, and the clinical "firm" eventually had its own wards for patients of all kinds, including psychogeriatric. As a result, it became possible to use the mental hospital as one element of an integrated series of facilities, rather than as a separate organization, whose communications with other services were formally structured and sometimes hostile.

All out-patient work, including after-care, was now arranged at the general hospitals, which were more acceptable to the population served and usually nearer their homes than the mental hospital. However, before any admission was arranged, joint consultation or screening occurred for as many cases as possible; this usually involved the psychiatrist and social worker, though most referrals originated from the GP, who was also present sometimes. Screening was often in the patient's home, or else in an out-patient clinic, day centre, hostel, or even the police station. Whereas seeking psychiatric care had usually been a bargaining process - often becoming a confrontation - it was now simply a choice between the various options of management. Whatever choice was made, the responsibility still remained with the same medico-social team, who dealt with it as well as they could within the limits of their resources. Except for patients at the periphery of psychiatric competence, particularly geriatric and personality disorders (where there might be boundary disputes with other services, or doubts as to the value of any medical intervention), it proved possible to eliminate the waiting list for mental hospital admission quite rapidly. Susser ${ }^{20}$ comments on these changes: "Almost at once patient care was rationalized. The psychiatrist's access to services at all levels enabled him to provide continuity in their long-term management. Through his participation and cooperation other changes gradually followed to rationalize the whole system." It was a relatively rare situation then for psychiatric consultation to be available to social workers virtually on demand, even though this might well be concluded by the return of responsibility to the social worker.

Also in 1961, the first mental health officer returned to the City Health Department from a university course as a trained PSW and was appointed Social Work Supervisor. From this time, an increasingly selective recruitment policy was followed so that by 1967 , only graduates were being appointed as trainee MWOs - a situation inconceivable in most parts of the country. Meanwhile, in-service training was developed, firstly under medical aegis and then by the social workers themselves; in this, the weekly meeting of all mental health staff was central, and its multidisciplinary nature was very unusual at the time. Similar meetings, on a smaller scale,

${ }^{20}$ Susser, op. cit., note 15 above, p. 267. 


\section{H. Freeman}

were developed at each of the individual facilities, in both hospital and local authority sectors - a method of management that was in total contrast to the traditional authoritarian hierarchies of both local government and mental hospitals.

In 1961-2 (before these changes had made any significant impact), a study of mental health social work in Salford and four other local areas was carried out by a team from Political and Economic Planning. At that time, the national average of MWOs to population was 2.3 per 100,000, whereas Salford's figure was 4.2, which was more than four times that for West Sussex, where the "Worthing Experiment" was going on. ${ }^{21}$ Just over half the Salford clients were diagnosed as psychotic, twenty per cent as neurotic, and fifteen per cent as suffering from personality or behaviour disorders; the bulk of the clients had been well known to the service for some time. Commenting on these results, Rehin and Martin ${ }^{22}$ state that the Salford social workers focused more on GPs and other health services than on the psychiatric hospital, whilst a relatively high proportion of interviews (forty-one per cent) were initiated by GPs. However, the model of community care used in the study, which was derived from the ethos of the Mental Health Act, stressed "the general medical nature of the psychiatric process", and did not favour psychiatric assessment depending upon a prior selection of patients by social workers. In subsequent years, as the administrative incoordination of services in Salford was resolved, this situation changed so that there was much more direct referral between GP and psychiatrist, but a similar problem was to recur twenty years later with community psychiatric nurses.

\section{FURTHER DEVELOPMENTS}

By the end of 1962, there were indications that the new organization of care was beginning to make itself felt, in that the proportions of compulsory admissions had fallen, the proportion of referrals to the Health Department being admitted had also become less, whilst the number of referrals being seen as out-patients relatively increased..$^{23}$ The end of that year also saw another change, in the opening at Hope Hospital of a ward, staffed by nurses with psychiatric training, though for the next eight years, some beds in it were used by the geriatric department; whereas there had only been eleven admissions to psychiatric beds at Hope in 1961, there were fifty in 1965. Some of this increase must have represented cases who would not have been considered severe enough to need admission to a mental hospital, yet who could benefit from appropriate in-patient treatment. Though adequate day facilities were not provided there until 1967, this was overcome to some extent by arranging for inpatients to attend the nearby local authority day centre (Cleveland House), which now accepted some male patients also.

This was one of a number of ways in which NHS and local authority services gradually interlocked like a jig-saw, each sector complementing the other. However, the therapeutic social club - which had been the local authority's first extra commitment to mental health - appeared to be losing support, and this change was not

${ }^{21}$ J. Carse, N. E. Panton, and A. Watt, 'A district mental health service. The Worthing Experiment', Lancet, 1958, i: $1218-1220$.

${ }^{22}$ Rehin and Martin, op. cit., note 4 above.

${ }^{23}$ City of Salford, Report of the Medical Officer of Health for 1962. 


\section{Mental health services in an English county borough before 1974}

peculiar to Salford. Jones ${ }^{24}$ states that these clubs had a comparatively short-lived vogue around this period, their functions being later taken over by group therapy or by less specialized clubs, while in mental hospitals, the standard of patients' sociability dropped as the less handicapped ones were discharged. However, for several years, Springfield Hospital in-patients went regularly out to this club in the city, on one evening weekly, giving some long-stay cases a rare opportunity to experience life outside hospital, while some male patients went to the local authority rehabilitation centre during the day. There was still support, though, for the club for younger subnormal adults, and a new one was started for younger psychiatric patients, most of whom had not had mental hospital experience. This paralleled the establishment of a separate younger group at Cleveland House during the day, which was particularly valuable in view of the total absence at the time of adolescent psychiatry in the hospital service.

In such ways, there was a flexible use of available resources, rather than a rigid assessment to one sector of care, thereby cutting off access to all others, which had been the traditional pattern in psychiatry. The different professions involved also began to step outside their habitual boundaries, though psychiatric nurses could do this to only a very limited extent because of their hierarchical organization within the hospitals, and it was to be another decade before the first community psychiatric nurses started work.

A major development in 1965 was agreement between the local authority and Springfield Hospital Management Committee to establish a new joint post for a mental health social worker, for which each was to pay half the cost. This social worker was attached to the Salford "firm" at the hospital, and once the principle was established, the same arrangement was later extended to the general hospitals, and the number of posts increased to four. The one PSW based at Springfield did all her work within the hospital, and the same was true of the only one at Prestwich; compared with the rigidity of their roles, these new arrangements were revolutionary. Another administrative step towards integration in the same year was the transfer of the city's child guidance clinic from the Education to the Health Department; because of its long waiting list, two supplementary clinics were established by the Health Department, run by its own doctors, to give counselling for less serious family problems. Here again, the style of improvisation and unconventional enterprise which had been initiated by Dr Burn was used to overcome lack of specialist resources, but the local authority came to feel - with much justification - that it was carrying more than its share of the mental health burden.

In 1966, the consultant psychiatrist who had been attached to the general hospitals in Salford retired, and his successor took on the same overall spread of responsibilities as the present author, whose rather lonely position of being the only person to straddle all aspects of the service was now shared. By this time, the Mental Health section of the local authority service was clearly under the operational direction of a social worker - the Chief MWO - though remaining administratively within the MOH's department. This represented a by-passing of traditional municipal bureaucracy, made possible by the goodwill of the individuals concerned, but matters of policy

${ }^{24}$ Jones, op. cit., note 18 above. 


\section{H. Freeman}

would often be taken jointly to the MOH by the MWO and Medical Officer for Mental Health, usually after discussion with the consultant psychiatrists and other social workers. Bennett ${ }^{25}$ commented that "Care can only be integrated if the professional staff are prepared to work in this way and themselves become the facilitators, co-ordinators and integrators of the system", a view which is supported by the experience of Salford at this time. By comparison, in 1960, only one out of six English local authorities either employed a PSW or had invested a member of its medical staff with special responsibility for mental health services. ${ }^{26}$

In 1966, the concept of Community Health Teams, developed from multidisciplinary discussions, came to fruition. These consisted of one or more GPs, a district nurse, midwife, health visitor, and mental health social worker; the purpose was to offer appropriate help to families in need as early as possible by improving communication and co-operation between the different professional workers. Six teams were formed, most of which functioned well for several years, but there were not enough social workers to extend the arrangement any further, while it became clear that only a small minority of GPs were prepared to take part in them in a meaningful way. However, all GPs were given a named social worker for liaison purposes, and this sometimes resulted in a close working relationship. Another innovative arrangement occurred at the psychiatric hostel (a former old people's home), where it had proved impossible to recruit suitable full-time staff at the existing salaries. Two social workers (a married couple) were given a mixture of intramural and extramural duties, with intermittent help from other members of the social work staff, particularly the trainees. Mountney ${ }^{27}$ pointed out that most local authorities that opened psychiatric hostels lacked a clear conception of what the rehabilitative function should be, or how it should be achieved; this was in contrast to the competence shown by voluntary organizations, such as the Richmond Fellowship. In Salford, weekly staff-resident meetings, attended by the Chief MWO, proved to be an effective means of social control in the hostel, without the need for irksome house rules. This hostel was always full, unlike the frequent under-occupancy elsewhere, ${ }^{28}$ which was mainly due to the fact that other such facilities were not integral parts of a total psychiatric service.

During 1967-68, there were improvements in the hospital physical facilities, which included a new out-patient clinic and occupational therapy department at Hope Hospital and the conversion of two wards at Springfield into an open-door, mixed admission unit for Salford patients, with a central office and secretary for the firm. This was a concept totally at variance with the traditional pyramidal authority structure of mental hospitals.

\section{THE LAST PHASE}

The period 1966-69 was undoubtedly the plateau of the integrated service when, in

${ }^{2 s}$ D. H. Bennett, 'Community psychiatry', Br. J. Psychiat., 1978, 132: 209-220.

${ }^{26}$ Rehin and Martin, op. cit., note 4 above.

${ }^{27}$ G. H. Mountney, 'Transitional accommodation', Paper given at a conference on psychiatric care in the community, London, Royal Society of Health, 1969.

${ }^{28} \mathrm{R}$. Apte, 'The local authority hostel as a transitional institution' in Freeman and Farndale (editors), op. cit., note 13 above, pp. 667-677. 


\section{Mental health services in an English county borough before 1974}

Fryers' view, 29 "[it] developed a sense of unity and an actual degree of working together probably unique in Britain". In 1969, five qualified PSWs were working in the Salford Health Department, which was more than the rest of the North West region had altogether. The psychiatric doctors and social workers at this time shared a practical and problem-orientated philosophy of doing what could be done; their relationship was based on a respect for what the other profession could achieve, yet also a realistic recognition of the limits of role competence. There were then many unfilled social work posts in other local authorities, often with higher salaries than Salford offered, so those social workers who came did so only for professional fulfilment, which involved a great variety of inter-staff relationships, in addition to those with patients. It also meant operating in a setting of democratic discussion, informal administration, and a constant search for innovative solutions. The model used by both professions (and by the nurses) was largely a medical one; this did not mean a neglect of the social context of psychiatric disorder, but rather a concern with those aspects of the client's milieu which were susceptible to professional intervention. At this time, a great feeling of optimism enveloped those psychiatrists and social workers throughout the country who were developing new forms of psychiatric services; they believed that the problems of mental illness were susceptible to professional skills, if only enough resources could be obtained to do so.

However, even then the situation contained a fundamental contradiction, which was the very meagre level of reward received by social workers of high ability and professional competence, at a time of rising expectations and concern for social justice. In many other places, experienced social workers were obliged to acknowledge the "supervision" of doctors who might well have much less expertise than themselves in these matters. The Seebohm Report ${ }^{30}$ appeared in 1968, recommending unified local authority social services, staffed by generically trained workers, and including all mental health services outside the NHS. This paper will not attempt to discuss the merits or otherwise of the social work reorganization; however, where doctors and social workers operated closely together, as they did in Salford, the inequity of the prevailing "officer and NCOs" system was inescapable, even though it never affected the cordial relationships between the two groups there. Unfortunately, the Seebohm solution, by "integrating" all forms of social work, caused a split in the integration of mental health services, where this had boen achieved, as well as destroying much of the laboriously developed expertise of psychiatric social work.

The local authority mental health service in Salford became part of the new generic Social Services Department in April 1971; just before that, the medical component of the service had come to an end with the departure of the Medical Officer for Mental Health to an academic post. With the huge increase in scale of the new social services organization, it proved impossible for the kind of intimate working relationships which the clinicians had previously enjoyed with those in charge of the local authority mental health service to continue. Though the weekly case conferences went on for some time, they seemed to be attended by a shifting population of social workers,

${ }^{29}$ T. Fryers, 'Psychiatric in-patients in 1982 - how many beds?', Psychol. Med., 1974, 4: 196-211.

${ }^{30}$ Seebohm Report, Report of the committee on local authority and allied personal social services, Cmd. 3703, London, HMSO, 1968. 


\section{H. Freeman}

often with little apparent knowledge of mental health problems or overt concern for them.

Nationally, the new social services seemed to have difficulty in accepting the chronicity of problems such as mental subnormality or schizophrenia, where longterm support was needed, together with practical help at times. It was particularly in respect of these kinds of clients that the vacuum created by the evolution of social work in a different direction resulted in it being filled by a newly emerging professional group - community psychiatric nurses. Furthermore, in areas with overwhelming social problems such as Salford, ${ }^{31}$ other duties and Government priorities (without extra resources) continually tended to push the mentally disordered into the background. Wooff, ${ }^{32}$ using data from the Salford Psychiatric Case Register, showed that whereas in 1968-72 referrals for mental health social work were fairly consistent, with an average of 458 per annum, these fell to 283 in 1973 and 259 in 1974. The most likely explanation for this change is that the former experienced mental health staff were moving into other posts and being replaced by social workers without such expertise, who did not recognize psychiatric problems.

Over the next few years, the specialized staff of mental health social workers was gradually rebuilt, but based wholly in the hospitals; correspondingly, the Register showed a slow return of social work referrals to the pre-1973 rate, which had been slightly exceeded by $1978 .{ }^{33}$

In 1970, the psychiatric out-patient clinic at Salford Royal Hospital was closed, since its isolation from the rest of the hospital psychiatric facilities had proved an increasing handicap; all out-patients were now seen at Hope Hospital. In the same year, a child psychiatry out-patient clinic was opened at the nearby children's hospital; shortly afterwards, it proved impossible to replace the retiring medical director of the Salford child guidance clinic, and its work was gradually transferred to the hospital service. In 1972, following a general review of psychiatric catchment areas in Greater Manchester by the RHB, there was a return to the pre-1956 arrangement, whereby mental hospital care for Salford patients was provided at Prestwich Hospital. In geographical terms, this made quite good sense, but for the consultant psychiatrists, it meant starting at the beginning again to re-create the Salford "firm", which had been set up with such difficulty at Springfield Hospital. These further changes had just about been digested when reorganization of both the NHS and local government was announced for April 1974, as well as the designation of several of the Salford hospitals as teaching hospitals for Manchester University Medical School, which included the psychiatric unit at Hope Hospital: Salford now became a Metropolitan District within the Greater Manchester County, with its population more than doubled and its area increased even more. From the NHS point of view, an Area Health Authority was established, coterminous in boundaries with those of the new city, but also managing Prestwich Hospital on an extra-territorial basis; this was a substantially larger

${ }^{31}$ V. J. P. Scerri, 'The mental health of an industrial city', Paper given at the Health Congress of the Royal Society of Health, 1974.

${ }^{32} \mathrm{~K}$. Wooff, unpublished MSc. thesis, Department of Community Medicine, University of Manchester, 1978.

${ }^{33}$ K. Wooff, H. L. Freeman, and T. Fryers, 'Psychiatric service use in Salford: A comparison of pointprevalence ratios 1968 and 1978', Br. J. Psychiat., 1983, 142: 588-597. 


\section{Mental health services in an English county borough before 1974}

organization than the Salford Hospital Management Committee, and it absorbed all the functions of the former City Health Department except environmental health.

\section{CONCLUSIONS}

In Britain and similar countries, the mental hospital was the foundation of psychiatric care for about a century; alternative developments began on a small scale in the 1920s, but in Salford not until 1944. The significant changes in psychiatric care in the post-World War 2 period have been subsumed under the heading of "deinstitutionalization", though Jones ${ }^{34}$ refers to them as "Three Revolutions", i.e., pharmacological, administrative, and legislative. Another significant term of the period was "community care", which Bennett points out ${ }^{35}$ began as an attempt to provide treatment for psychiatric patients outside the mental hospital, but evolved into a national plan to provide district-based services in which general hospital units and social services complemented each other. The processes of deinstitutionalization and community reorientation, together with that of full responsibility for a defined population, were of crucial importance in the later developments in Salford. It should also be noted that it was in other compact county boroughs of medium size (Croydon, Oldham, Nottingham, York, etc.), that developments towards integration also occurred at about the same time. In such places, the number of key professional staff was small enough for all to remain in regular personal touch, yet large enough to embrace a reasonable range of skills.

However, in many similar towns there was little or no progress with developing mental health services; in seeking reasons why Salford's experience was different, the quality of its MOH in the 1950s and 60s, Dr J. L. Burn, seems to be crucial. As Muir Gray ${ }^{36}$ has commented on the early Public Health Movement in England, "Essential for change to occur are changeurs, those individuals and groups who have the commitment and ability to realize the potential energy for change." Probably the most important single step taken by Dr Burn in this respect was to bring in the help of academic doctors, particularly Dr M. W. Susser, who steered the local authority service away from its traditional hierarchical methods to a professional and open orientation. When the hospital sector also began to change, through new consultant appointments, there was a rare conjunction of the influential posts in both spheres being occupied at the same time by professional staff who were committed to a community orientation. The managerial character of the NHS meant that there were no constraints on its consultants from any need to seek a wider mandate, e.g., from those holding political power locally. In Salford, the virtual absence of private practice simplified integrative arrangements for the services.

Salford may be seen as a forerunner from the mid-1950s of the important trends of British mental health services in the third quarter of this century. It showed the typical features of "inner city" decline, except for its relatively small numbers of immigrants and transients. Although adhering generally to the medical model, the mental health service also practised "social psychiatry" in terms of its acknowledgement of the

\footnotetext{
34 Jones, op. cit., note 18 above.

${ }^{35}$ Bennett, op. cit., note 25 above.

36 J. Muir Gray, Men against disease, Oxford University Press, 1979.
} 


\section{H. Freeman}

importance of social factors in illness and treatment, and in the close collaboration between its medical and social services. In its deficiencies, e.g., poor services for children and adolescents, and limited provision for drug dependence and of psychotherapy, it reflected British psychiatry in general. Where it succeeded most was in maximizing the use of limited resources, and thus making medical psychiatric care readily available to people in the population suffering from psychiatric morbidity.

\section{ACKNOWLEDGEMENTS}

Valuable comments were made on the material in this paper by Prof. L. F. Baric, Dr Tom Fryers, Mr G. H. Mountney, and Dr John Pickstone. The generous help of the Rockefeller Foundation, through the author's period of residence at the Villa Serbelloni, is gratefully acknowledged. 